\title{
A short review: Effectiveness combination with glass ionomer cements and chemo-mechanical caries removal.
}

\author{
Yoshishige Yamada \\ Department of Conservative Dentistry, Ohu University School of Dentistry, Japan
}

\begin{abstract}
Introduction: Glass ionomer cements are effective restoration materials because of the ability of fluoride ion releasing and chemical adhesion to a tooth enamel and dentin. Glass ionomer cements are divided into conventional type which is adhered to a tooth by an acid-base reaction, and resin-modified type which is included some of resin components and has an adhesion using mechanical fitting force. Although these cements have good bonding strength to a tooth, this chemical adhesiveness is not sufficient, therefore adhesive monomer addition in the glass ionomer cements have effectiveness improving adhesive ability between glass ionomer cements and teeth. Glass ionomer cements restoration is applied in several situations. Among them, the application of glass ionomer cements to the ART method is very effective.

Method: ART technique is known to use hand instruments and glass ionomer cements. This technique is very effectiveness for the treatment of Children who have difficulties in dental treatment and patients with dental phobia. However, this technique takes longer time to remove caries than conventional methods. To resolve this problem, using chemo-mechanical caries removal is effective method. This method is able to shorten caries removal time without affecting adhesion of glass ionomer cements to the tooth.

Conclusion: Therefore combination with chemo-mechanical caries removal and glass ionomer cements restoration is effective to obtain satisfied caries treatment.
\end{abstract}

Keywords: Glass-Ionomer cements, ART technique, Chemo-mechanical caries removal.

Accepted date: September 21, 2018

\section{Introduction}

Ordinary, Composite resin is mainly selected as a filling martial for caries treatment. However, it is most important factors for perform certain composite resin filling should be an advanced reliable moisture proof treatment and an appropriate pretreatment process.

If the treatment is performed under inappropriate circumstances without above requirement, it will be difficult to achieve adequately adhesion between the composite resin and the tooth. Consequently, risks of filling material desorption or occurrence of secondary caries might be extremely increased.

The case of hard to maintain dry condition should be chosen glass ionomer cements to filling materials instead of composite resin. Because glass ionomer cements are hydrophilic material that is containing water in their components. Therefore even in a slight wet condition, the degree of polymerization inhibition is lower than that of a composite resin. Glass ionomer cements that are also known as glass polyakenoic cements and were introduced as derivative of the silicate cements and the polycarboxylate cements.

Although glass ionomer cements were initially developed and used for crown restoration as an aesthetic filling material [1,2], at a late time this cements also used as a luting cement for indirect restoration material such as crown, bridge and orthodontic and cementation $[3,4]$.
The advantages of glass ionomer cements are that (a) they adhesive to enamel and dentin; (b) they have good biocompatibility to the pulp and surrounding soft tissues [5]; (c) Their coefficient of thermal expansion is similar to dentin, therefore, gap formations are hard to occur between the glass ionomer cements and the tooth during polymerization; (d) They release fluoride ion for a long period. It is a great advantage for change hydroxyapatite into fluoroapatite, obtaining an acid resistance and reduces secondary caries occurring [6-8]. Long period of fluoride ion releasing has particularly advantageous for high susceptibility to dental caries.

\section{Classification of glass ionomer cements}

Glass ionomer cements have been classified for clinical use as follows

Type (I): Luting cement for crowns, bridge, and orthodontic brackets. Type (II)a: Esthetic restorative cement, Type (II)b: Reinforced restorative cement, Type(III): Lining and Base. Another classification of glass ionomer cement by their composition is as follow. Typical glass ionomer cements are mainly classified into conventional glass ionomer cement and resin-modified glass ionomer cement. Conventional type of glass ionomer cement (CGI) was first produced in 1972 by Wilson and Kent [9]. 
Citation: Yamada Y. A short review: Effectiveness combination with glass ionomer cements and chemo-mechanical caries removal. J Clin Dentistry Oral Health 2018;2(1):9-12.

Main components of conventional glass ionomer cement are Fluoro-aluminosilicate glass and polyacriric acid. This cement has an ability of adhesion to tooth structure. The mechanism of this chemical adhesion is based on the acid-base reaction (chelate bonding) both polyacrylate ion in a glass ionomer cement and calcium ion derived from hydroxyapatite in a tooth structure [10,11].

In the late 1980s, Resin-Modified Glass Ionomer Cements (RMGI) has been developed [12]. RMGI formed by replacing part of the polyacrylic acid in conventional glass ionomer cements with polymerizable functional methacrylate monomers [13]. The main of this methacrylate monomer is HEMA that is hydrophilic monomer, and it has high tissue permeability. Adhesive mechanism of RMGI are not only acidbase reaction, but also mechanical mating force generated by forming a penetration layer similar to the resin impregnated permeable layer as a result of permeation of resin components.

\section{Comparison of both glass ionomer cements}

Polymerization reaction and chemical adhesive with tooth structure are based on the occurring of acid -base reaction after mixing the powder and the liquid (curing is based on the chemical polymerization). On the other hand, curing of polymerization of RMGI is also able to cure by light irradiation because of including Photo polymerization catalyst in it.

Exposure to water and saliva contamination at the initial stage of polymerization has been shown to significantly increase the solubility and decrease the ultimate hardness of conventional glass ionomer cements, therefore the process of covering cement surface with coating agent is important to avoid this weak point. While RMGI are not necessary considering this process because cements surface are cured immediately by light irradiation.

Moreover RMGI shows improved adhesion to tooth structure, high compressive, tensile strength compared with CGI.

Previous researchers were insisted that the leakage level of RMGI were less noticeable than CGI in the results of microleakage test [14-17]. However none of complete marginal sealing was demonstrated in any previous study. Therefore to achieve complete marginal sealing further glass ionomer cements improvement should be necessary.

\section{Glass ionomer cements with adhesive monomer}

One of the answers of this problem might be to include adhesive monomer in the cements. Recently glass ionomer cements containing with adhesive monomer have been developed and applied clinically as luting cements. The characteristic of these cement are seemed to locate between glass ionomer cements and resin cements.

Glass ionomer cements with adhesive monomer have shown the lower marginal leakage level than CGI and RMGI [18]. Unfortunately, these cements mainly have been using for cementation. Therefore, further development for cements with adhesive monomer for crown restoration is desirable.

\section{Chemo-mechanical caries removal method}

Caries treatment of young children or dental phobia patients is sometimes difficult by using rotary instruments. In such case, hand instruments should be selected instead of rotary instruments for the caries removal.

The technique of combination using glass ionomer cements and hand instrument has been known as ART (A Traumatic Restorative Treatment) technique [19,20].ART technique has been developed under the aegis of the World Health Organization with the aim of providing dental care for countries which have not maintained stable power supply device, then rotary instruments (electrically driven drills and burs) cannot be used routinely. To address these problems, ART technique has been developed and introduced to various countries throughout the world. ART technique uses hand instruments to remove caries dentin and enamel, and then glass ionomer cements are used as cavity filling materials. However this technique has a serious problem that the treatment time should be taken longer than a conventional caries removal method.

Therefore additional technique to improve caries removal time is desirable. One resolution of this problem is combination used Chemo-Mechanical Caries Removal (CMCR) method. The chemo-mechanical caries removal method is aimed at softening dental caries by special agent and then removal of caries dentin by hand instruments easily $[21,22]$.

The CMCR method is capable of removing caries dentin safely and efficiently with CMCR agent and hand instruments. This method is easy to accept to the patients who are difficult to perform dental treatment using conventional rotary instruments. Regarding the chemical substances in caries removal, chemo-mechanical caries removal system such as GK-101, Caridex has been reported $[23,24]$. Their system was used special agent with the pharmacodynamics action of sodium hypochlorite. Recent over 10 years, Carisolv ${ }^{\mathrm{TM}}$ system $^{\mathrm{a}}$ and Papacarie ${ }^{\circledR}$ system have been developed and been using to dental caries removal. Carisolv ${ }^{\mathrm{TM}}$ which contains sodium hypochlorite and three kinds of amino acids (glutamic acid, leucine, and lysine) [25-27]. While the main component of Papacarie $^{\circledR}$ is papain enzyme $[28,29]$.

\section{Benefit of combination CMCR and glass ionomer cements}

It has been demonstrated that there is nothing any influences to composite resin restoration after using these two cariesremoving agents $[21,22,30]$.

Moreover it has also been reported that the use of CMCR agents to caries removal does not affect glass ionomer cements restoration [16,31]. Therefore, it seems that combination with CMCR method and glass ionomer cements restoration can be a therapeutically effective option for patients who are difficult to use conventional rotary instruments and composite resin materials such as young children, dental phobia and home care patient. 


\section{Conclusion}

Glass ionomer cements have ability to fluorine ion, induce acid resistance of tooth and inhibit secondary dental caries.

The CMCR method is useful as a treatment for patients who have difficult using conventional caries removal rotary instrument.

By adopting this treatment method, it is possible to remove of caries safely and securely, and acquired acid resistance of tooth structure. Therefore this combination method might be desirable candidate caries treatment, not only Children who have difficulties in dental treatment and patients with dental phobia, and but also general patient.

\section{References}

1. Phillips RW. The restoration of eroded cervical areas. CDS Rev. 1980;73(4):31-4.

2. McLean JW. New concepts in cosmetic dentistry using glass-ionomer cements and composites. CDA J. 1986;14(4):20-5.

3. Chang B, Goldstein R, Lin CP, et al. Microleakage around zirconia crown margins after ultrasonic scaling with selfadhesive resin or resin modified glass ionomer cement. J Esthet Restor Dent. 2018;30(1):73-80.

4. Attar HE, Elhiny O, Salem G, et al. A Twofold Comparison between Dual Cure Resin Modified Cement and Glass Ionomer Cement for Orthodontic Band Cementation. Open Access Maced J Med Sci. 2016;4(4): 695-9.

5. Mount GJ. Clinical performance of glass-ionomers. Biomaterials. 1998;19(6):573-9.

6. Tam LE, Chan GP, Yim D. In vitro caries inhibition effects by conventional and resin-modified glass-ionomer restorations. Oper Dent. 1997;22(1):4-14.

7. Han L, Abu-Bakr N, Okamoto A, et al. Study of the fluoridated adhesive resin cement--fluoride release, fluoride uptake and acid resistance of tooth structures. Dent Mater J. 2001;20(1):114-22.

8. Naik NS, Subba Reddy VV, Shashikiran ND. Comparative evaluation of secondary caries formation around lightcured fluoride-releasing restorative materials. J Indian Soc Pedod Prev Dent. 2017;35(1):75-82.

9. Wilson $\mathrm{AD}$, Kent BE. A new translucent cement for dentistry. The glass ionomer cement. $\mathrm{Br}$ Dent $\mathrm{J}$. 1972;132(4):133-5.

10. Davidson CL. Advances in glass-ionomer cements. J Appl Oral Sci. 2006;14:3-9.

11. Khoroushi M, Keshani F. A review of glass-ionomers: From conventional glass-ionomer to bioactive glassionomer. Dent Res J (Isfahan). 2013;10(4):411-20.

12. Wilson AD. Resin-modified glass-ionomer cements. Int $\mathrm{J}$ Prosthodont. 1990;3(5):425-9.

13. Yli-Urpo H, Lassila LV, Närhi $T$, et al. Compressive strength and surface characterization of glass ionomer cements modified by particles of bioactive glass. Dent Mater. 2005 ;21(3):201-9.
14. Yamada Y, Kimura Y, Manabe A, et al. Adhesiveness of various glass ionomer cements in cavities treated with Carisolv. J Clin Pediatr Dent. 2012;37(2):183-7.

15. Pontes DG, Guedes-Neto MV, Cabral MF, et al. Microleakage evaluation of class $\mathrm{V}$ restorations with conventional and resin-modified glass ionomer cements. Oral Health Dent Manag. 2014;13(3):642-6.

16. Sharafeddin F, Feizi N. Evaluation of the effect of adding micro-hydroxyapatite and nano-hydroxyapatite on the microleakage of conventional and resin-modified Glassionomer $\mathrm{Cl} \mathrm{V}$ restorations. $\mathrm{J}$ Clin Exp Dent. 2017;9(2):e242-8.

17. Diwanji A, Dhar V, Arora R, et al. Comparative evaluation of microleakage of three restorative glass ionomer cements: An in vitro study. J Nat Sci Biol Med. 2014;5(2): 373-7.

18. Yamada Y, Kimura Y, Kikui T. Evaluation of Glass ionomer cement restoration after chemo-mechanical removal of caries. Jpn J Conserv Dent. 2018;61(3):190-9.

19. de Medeiros Serpa EB, Clementino MA, Granville-Garcia $\mathrm{AF}$, et al. The effect of atraumatic restorative treatment on adhesive restorations for dental caries in deciduous molars. J Indian Soc Pedod Prev Dent. 2017;35(2):167-73.

20. Giacaman RA, Muñoz-Sandoval C, Neuhaus KW, et al. Evidence-based strategies for the minimally invasive treatment of carious lesions: Review of the literature. Adv Clin Exp Med. 2018;27(7):1009-16.

21. Divya G, Prasad MG, Vasa AA, et al. Evaluation of the Efficacy of Caries Removal Using Polymer Bur, Stainless Steel Bur, Carisolv, Papacarie - An Invitro Comparative Study. J Clin Diagn Res. 2015;9(7):ZC42-6.

22. Nouzari A, Zohrei A, Ferooz M, et al. Marginal Microleakage of Self-etch and All-in One Adhesives to Primary Teeth, with Mechanical or Chemo-Mechanical Caries Removal. J Dent Biomater. 2016;3(2):220-5.

23. Habib CM, Kronman J, Goldman M. A chemical evaluation of collagen and hydroxyproline after treatment with GK-101 (N-Chloroglycine). Pharmacol Ther Dent. 1975;2(3-4):209-15.

24. Schutzbank SG, Galaini J, Kronman JH, et al. A comparative in vitro study of GK-101 and GK-101E in caries removal. J Dent Res. 1978;57(9-10):861-4.

25. Ericson D, Zimmerman $\mathrm{M}$, Raber $\mathrm{H}$, et al. Clinical evaluation of efficacy and safety of a new method for chemo-mechanical removal of caries. A multi-centre study.Caries Res. 1999;33(3):171-7.

26. Lai G, Lara Capi C, Cocco F, et al. Comparison of Carisolv system vs traditional rotating instruments for caries removal in the primary dentition: A systematic review and meta-analysis. Acta Odontol Scand. 2015;73(8):569-80.

27. Keenan AV, Congiusta MA. Efficacy of using Carisolv in the removal of decayed tooth structure in primary teeth. Evid Based Dent. 2016;17(2):44-5.

28. Bussadori SK, Castro LC, Galvão AC. Papain gel: a new chemo-mechanical caries removal agent. J Clin Pediatr Dent. 2005;30(2):115-9. 
Citation: Yamada Y. A short review: Effectiveness combination with glass ionomer cements and chemo-mechanical caries removal. J Clin Dentistry Oral Health 2018;2(1):9-12.

29. Hafez MA, Elkateb M, El Shabrawy S, et al. Microleakage Evaluation of Composite Restorations Following PapainBased Chemo-Mechanical Caries Removal in Primary Teeth. J Clin Pediatr Dent. 2017;41(1):53-61.

30. Nair S, R Nadig R, S Pai V, et al. Effect of a Papain-based Chemomechanical Agent on Structure of Dentin and Bond Strength: An in vitro Study. Int J Clin Pediatr Dent. 2018;11(3):161-6.

31. Hamama H, Yiu C, Burrow MF. Effect of chemomechanical caries removal on bonding of resinmodified glass ionomer cement adhesives to cariesaffected dentine. Aust Dent J. 2015;60(2):190-9.

\section{*Correspondence to}

Yoshishige Yamada

Division of Operative Dentistry, Department of Conservative Dentistry

Ohu University School of Dentistry,

31-1 Misumido, Tomita-machi, Koriyama-city, Fukushima 963-8611, Japan.

Tel: +81-24-932-8931

FAX: +81-24-932-9285

E-mail: y-yamada@den.ohu-u.ac.jp 